\title{
Numerical Code-Switching in Khuzestani Arabic
}

\author{
Hossein Matoori \\ Islamic Azad University - TEFL Department - International Branch of Khorramshahr - Persian Gulf, \\ Khorramshahr, Iran \\ hsn_matoori@yahoo.com
}

\begin{abstract}
This paper aims to pinpoint a case of language contact in Khuzestani Arabic- a vernacular spoken in southwest of Iranwhere Iranian Khuzestani Arab bilinguals use code-switching in their conversations with numbers. There has not been much research on Khuzestani Arabic vernacular particularly from a sociolinguistics point of view. The way Khuzestani Arabs switch from Arabic to Persian (Farsi) when incorporating numbers into their conversations has triggered the main impetus for this research. After studying and analyzing some samples of their speech, it has been found that this codeswitching is surprisingly systematic and rule-governed. The result of this study shows that when scale is assigned to numbers describing weight, height, distance, price, and age, they are said in Arabic; whereas non-scale numbers describing digits, codes, contact numbers, serial numbers, or credit card numbers are said in Persian.
\end{abstract}

Key words: Khuzestani Arabic; Code-Switching; Numbers;

\section{Introduction}

Code-switching is a noticeable phenomenon of bilingual communities where people switch from one language to another. Pieter Muysken (2011) defines code-switching as "the use of more than language during a single communicative event". This code-switching has been the focus of some sociolinguistic research in the last three decades. Though much of the sociolinguistic research is interdisciplinary, most researchers working on this field generally have a good command of linguistics knowledge as well.

In this research an attempt has been made to explore a case of code-switching in a bilingual community in Khuzestan - a province in southwest of Iran- where people speak Arabic and Persian. There is no estimate of the population of Khuzestani Arabs in Iran. But an unofficial estimate is between three to five million speakers across Iran. The majority of this bilingual community is Shia, Muslim. This Arabic community is highly bound and attached to their religious and traditional thinking. It is worth noting that Khuzestani Arabic, very similar to the dialect of Iraqi Arabic, is a vernacular just spoken by this Arabic community. There are no Arabic schools in Khuzestan. Khuzestani Arabic continues to survive under Persian, the dominant official language of Iran. Persian as the dominant language has exerted some influence on Khuzestani Arabic resulting in some linguistic changes. A study by Shabibi (2006) could state only a few grammatical changes (syntactic order) among many others. There are some other changes that need some thorough and comprehensive research.

Whatever the status of this language is, and whatever changes it has gone through, Khuzestani Arabic is an indigenous vernacular surviving under Persian - the dominant official language of Iran. One of the most noticeable features of bilingual communities is code-switching; Khuzestani Arabic is not an exception. Bilingual Khuzestani Arabs tend to switch between Arabic and Persian or vice versa when talking to their bilingual interlocutors. Bilinguals sometimes handle code-switching quite subconsciously not being aware they're doing so, although some code-switching could be done quite consciously Holmes (2008), Holmes \& Hazen (2014), and Wardhaugh (2010). Some researchers like Myers-Scotton (1998) focus on intersentential aspect of code-switching while others are interested in intrasentential features. Complement phrase or maximal projection is also gaining some interest amongst code-switching researchers. Some are interested in the structure and processing of numbers in bilinguals (Macizo, et al 2010, Roberts, 2000, Bialystok 1997 and Frenck-Mestre et al 1993). These researchers are interested in the way bilinguals employ numbers or some simple mathematics functions in their L1 and L2. Other Researchers like Frenck-Meystre \& Vaid (1993) worked on number formats -digits versus word- on bilinguals. The participants' accuracy and proficiency in solving numerical problems has been strongly focused in their research. They found that retrieval of numerical facts is format-sensitive not language-sensitive. Roberts (2000) tells us about how Welsh people have two number systems available to them and how this system operates differently in different context. Rarely has any researcher touched on the issue of code-switching numbers in bilinguals or multi-linguals.

In my Arabic-Persian bilingual community, it has been frequently observed that Arab bilinguals switch to Persian when they want to exchange contact information, basically phone numbers. That is, mobile and phone numbers are given in Persian in Khuzestani Arabic. This phenomena is so widespread that it is almost observable in most Khuzestani Arabic conversations engaged in exchanging numerical/contact information. These bilinguals tend to code-switch numbers so frequently that it is becoming a normal phenomenon. It means the whole conversation happens in Arabic but when they get to the contact number exchanging part, they suddenly switch to Persian. Although socio-demographic, historical, and political changes have some degree of effect on linguistic changes in general and code-switching numbers in particular, this research does not specifically intend to explore the historical reasons of code-switching but rather attempts to pinpoint the nature of a new phenomenon called numeral code-switching and also tries to explore certain numerical forms and groups that are code-switched. Code-switching numerals in Khuzestani Arab bilinguals seems to be pretty systematic and rule-governed rather than random or accidental. In order to better understand the scope of this study two research questions have been raised. 


\section{Reasearch Questions:}

1. What class of numbers are code-switched by Khuzestani Arab bilinguals?

2. Is numerical code-switching in Khuzestani Arabic rule-governed?

It has been observed that not all numbers are said in Persian but there is a certain class of numbers said in Persian. What numbers are said in Persian and what numbers are said in Arabic is the focus of this research. The characteristics of each group of numbers are linguistically and numerically explored and analyzed. The format and structure of each class of numbers plays a key role in initiating the numeral code-switching. Research on numeral code-switching, though a little novel and unique on its own, demands more comprehensive research on the part of sociolinguists and other field related researchers.

\section{Review of Literature}

There have been some works on numbers and bilingualism, but cases working on numerical code-switching in bilinguals are rare. Here we try to present the literature hierarchically from general to specific.

In an interesting study Rafiki Yohana Sebonde (2014) examined a case of code switching in Chasu language of Tanzania. In his study Sebonde found cases of lexeme switchings as well as numerical borrowing in a multilingual community where three languages are spoken: Chasu the host language, English and Swahili. He contends that numerical expressions are the most frequently borrowed lexicons below illustrates the numerals which were borrowed from Swahili and English and their frequency. His study also maintains that incorporating numbers in Chasu from is much more a case of borrowing rather than code-switching.

Some studies focus on mathematical competence of bilinguals and how mathematical functions are processed in in their competence (Clarkson, 2008). His study indicated that "Papua New Guinea bilingual students' competence in both their languages scored significantly higher on two different types of mathematical tests compared to colleagues who had low competence in their language". Although this study worked on bilinguals and numbers, it did not touch on the issue of code-switching.

Spelke and Tsivkin (2000) had an interesting numerical experiment on Russian-English bilinguals. They trained the bilingual participants some historical and geographical facts involving numerical or non-numerical information. They found that "subjects retrieved information about exact numbers more effectively in the language of training". In their findings they also focused on comparison of human and mammals language learning from a cognitive point of view and go on to say that natural language contributes to the representation of large, exact numbers but not to the approximate number representations that humans share with other mammals.

Bialystok (1997) examined monolingual and bilingual children's knowledge of metalinguistic and cardinality development. She contends that because bilingual children require higher levels of focus and attention to control and process language and numbers, they would be more skillful to handle cardinality and knowledge analysis and to solve problems. Her study focuses on how monolingual and bilingual children cognitively develop cardinality and knowledge processing. She does not deal with code-switching in bilinguals.

Macizo et al (2010) examined the compatibility effect of L2 on numerical information in two groups of German/English bilinguals with high and low fluency in L2. The study suggests that low fluency bilinguals showed verbal number comparison as monolinguals, while high fluency bilinguals did not demonstrate compatibility effects in either German or English. Their results indicate that $L 2$ learning plays a role in processing of two-digit number words.

In a very fascinating study Frenck-Mestre \& Vaid (2010) examined the effect of number formats in digits formats and word formats in the first and second language of bilinguals - on mental arithmetic. The study focused on the speed of numberfact retrieval and the presence of interference caused by numbers either numerically close to or associatively related to the correct answers of stored arithmetic problems. The problems verification was slower and less accurate from the digit format to the second-language condition. Interference was caused by both types of incorrect answers in the digit and firstlanguage conditions, while in the second-language condition, it was limited to answers that were numerically close to correct answers. The results suggest that the retrieval of arithmetic facts and the automatic spreading of activation within the network of numerical facts are not only language-sensitive, but format-sensitive in general.

The most related research to our current study of numerical code-switching is Gareth Roberts's article entitled "bilingualism and number in Wales". Gareth (2000) introduces three number systems in Welsh: the first system is English numbers, the other one is modified vigesimal system (MV) and the third one is decimal (D). For example a Welsh might have experienced 18 as: eighteen (English), 'un deg', and 'deunaw'. As a bilingual English-Welsh community, Welsh codeswitch when they want to refer to numbers. This numerical code-switching is mostly determined by historical and social factors. Gareth gives clear evidence from historical records where these three number systems were used. He also contends that in the last two decades Welsh has gained greater legitimacy due to social and political reforms of minority language rights through education and schooling in Welsh. Today's numeral code-switching of Welsh is mostly a matter of the social context in which these people are engaged. People tend to employ either of these three systems depending domains of religion, broadcasting and the media, education, business and commerce, and everyday conversational
1118| P a g e
Council for Innovative Research 


\section{ISSN $2348-3024$

contexts. He also adds age, sociological contexts, and educational background as determining factors for numerical codeswitching. What his articles misses to elaborate on is that the nature of the linguistic arrangement might determine numerical code-switching.

Our study is an attempt to discover how the nature of numerical items can effect numerical code-switching.

\section{Methodology}

\subsection{Participants}

Participants were chosen from Khorramshahr Islamic Azad University, Iran, studying law, accounting, food industry engineering, and computer science. All participants are Arabic-Persian bilinguals speaking Khuzestani Arabic (indigenous vernacular) as well as Persian, the official language. There are 16 males and 17 females ranging from age 18 to 47 . The participants were given anonymous codes so their personal information and privacy would be protected. See Appendix 1.

\subsection{Design and materials}

This study was conducted at Khorramshahr Islamic Azad University, Iran. Bilingual Khuzestani Arabic-Persian volunteers were asked to read the research ethics and volunteer for the study. In case they agreed to the terms and conditions of the research, they were asked to sign the consent forms. Students had to take part in an interview in Khuzestani Arabic. Students were interviewed at their convenience preferred time (especially between-class intervals and breaks) when they were present at university for their classes. Six dates and time were chosen and each student attended their interview as set. All the interviews were recorded by a digital voice recorder in a classroom at the University.

\subsection{Procedures}

The interviews were done in a classroom where students sat on a chair and they were greeted warmly. A voice recorder was already turned on placed on the chair. The interviews were intended to create a warm and friendly atmosphere so the participants would feel having a friendly chat. The interviews focused on eliciting samples of numerical code-switching, though interviewees were not aware of this. Students talked about general topics from their academic life to aftermath of Iran-Iraq war in 1980. The interviews were maintained in a way that the participants were the authorities and the interviewer avoided linguistics accommodation as much as possible. One general question was "Where did you move when war broke out?"

\section{Data Analysis and Results}

Three basic tokens of numerical code-switching which had a higher frequency of occurrence in the students' recorded conversations were analyzed: a) the way students stated their students' ID number, b) their telephone number, and c) the way they talked about years, periods of time, and duration. All this information is illustrated in table 1.

The word "Yes" on the table shows that students switched from Arabic to Farsi while the word "No" means that the students uttered the item in Arabic.

The data shows that students use code-switching when they want to say their student ID numbers and phone numbers. Statistically speaking, thirty students out of thirty three, over \%90.90 of them, used code-switching for these two items. The third column shows code-switching about years and age. Students talk about what year they started their study, what year they moved back to Khorramshahr or Abadan after 1988 ceasefire, and how old they are. The time column shows variations in code-switching. While $54.54 \%$ of the students code-switched over the first column of time (year $\left.{ }^{1}\right)$, the second column (year ${ }^{2}$ ) demonstrated only $3.03 \%$ of code-switching, that is, one out of 33 . The age column showed the most fascinating result with no code-switching.

There is a reason why some class of numbers are code-switched while others are not. But before we deal with detailed breakdown of these numbers, let's consider some parts of an interview with the student 1E from our table who used numerical code-switching. Students are assigned code numbers such as (1A, 2B, 3C etc.) to observe anonymity rights. Remember that all the conversation is in Khuzestani Arabic (an indigenous vernacular). Furthermore, it should be noted that students make use of solar calendar when they speak about dates ( e.g. 2015 equals 1394 in solar calendar)

$\mathrm{I}=$ Interviewer and $\mathrm{P}=$ Participant

$$
\text { I: [من يا سنه كَعد تدرس الكترونيك؟ }
$$

........ [since what year have you been studying electronics?

$$
\text { P }
$$

This year. No. no. Since ninety three

$$
\text { | : ...... : متولد يا سنه؟ }
$$

What year were you born?

$$
\text { P : هتاد و بنج }
$$


Seventy five

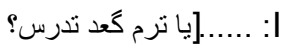

What semester are you in?

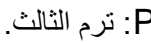

Third semester.

|

How old are you?

P P

Nineteen.

[شمار ه دانشجويى مالتك اشخد؟

What's your student ID number?

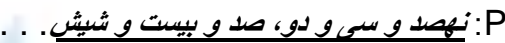

Zero, nine hundred thirty two, one hundred twenty six.

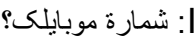

And your phone number?

. . صفر نهصد و سع ونه، جهارصد و جهل :P

Nine hundred thirty nine, four hundred forty, ...

The underlined parts show that the numbers are code-switched in Persian. These participants demonstrated some degree of code-switching over certain class of numbers. Though not all participants showed the same kind of code-switching, the majority of them almost had similar code-switching over certain class of numbers. Participant 1E was the most typical and extreme representative of code-switching numbers. 


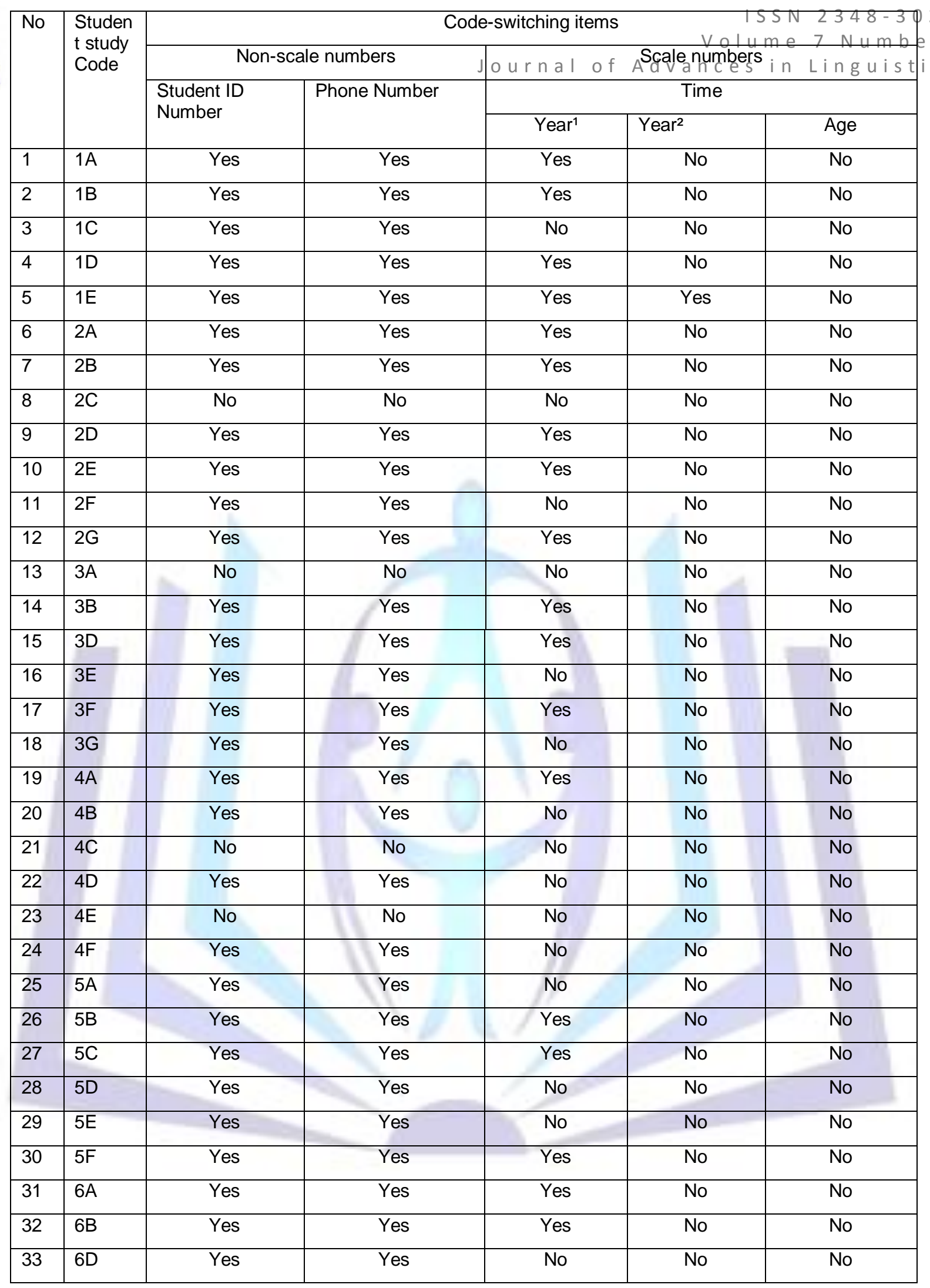

Table 1: Items that are code switched are shown by 'Yes' and items without code-switching are shown by 'No'.

1. referring to specific years such as: 1998,2009 , etc.

2. referring to a period of years such as: two years, five years, etc.

Now let's consider and analyze the nature of the numbers code-switched here. Note that the definitions and classifications of the numbers are all the researcher's own. If we break down the numbers on table 1, we see that the first two columns are single digits used to express phone numbers and students' ID numbers. There are some other numbers sharing this 
type of property. Bank account numbers, credit card numbers, serial numbers, and ISBN numbers are only a few to name. Basically no value is assigned to this class of numbers. It means that they do not represent any scale or measure but only used to express single digits for identification purpose.

On the other hand, the second class of numbers express value, scale, or measure. Numbers expressing age, length, height, distance, weight, etc. belong to this classification. Here in this paper the first class is called non-scale numbers and the second class is called scale numbers (our own classification and definition). In order to recall our research questions and answer them, let's state them here again: 1. What class of numbers are code-switched by Khuzestani Arab bilinguals? And 2. Is numerical code-switching in Khuzestani Arabic rule-governed? It has been found that Khuzestani Arabs quite frequently code-switched the first class while they rarely or almost never code-switch the second class. What plays a crucial role in this code-switching is the nature or the class of number in focus. Scale numbers are generally expressed along their scales/measures, that is, age, height, distance etc. For example: 25 years old, 2 meters, 60 kilometers, etc. In contrast, non-scale numbers are not presented along any measure or scale but rather stand alone as digits.

There is one column in table 1 that demonstrated a little fluctuating result. Scale number year ${ }^{1}$ column shows that participants perform different code-switching, some pertaining to Arabic, while others code-switched the year ${ }^{1}$ and expressed it in Persian.

It is worth mentioning again that Iran's official calendar is solar, for example, Oct/01/2015 equals 07/09/1394 on Iranian calendar. Lunar calendar is a second official calendar which is mostly used for Islamic religious events and occasions, along the solar calendar. For example, 10/01/2015 equals 12/17/1436 in a lunar calendar. Iranians generally use a solar calendar to talk about their date of birth and other events in informal/colloquial conversations. This feature is also true about Khuzestani Arabic where bilinguals apply the same date-reading system to talk about their date of birth or age. From a colloquial point of view, Iranians generally use the last two numbers to say their date of birth; for example, if some one's date of birth is 1365 , they only say the last two numbers which is 65 . The same format is employed in Khuzestani Arabic as well. This property of Iranian calendar seems to play a role in code-switching year ${ }^{1}$ column, though the reason of this code-switching is not quite clear.

It is somehow clear that code-switching occurs mostly with non-scale numbers while scale numbers are almost never code-switched; however, it is not clear why the scale number year ${ }^{1}$ shows such a varying fluctuation over code-switching. One similar number that was not a token of the interviews is asking about shoe size. When asked what size shoes you wear, Khuzestani Arabs show variable code-switching, some, for example, say اثثين و اربعين which means 42 while others code-switch to Persian and say جط: = forty two.

One interesting point about numerical code-switching in Khuzestani Arabic is the phonetic features of these code-switched numbers. When Khuzestani Arabs code-switch a number, they preserve the Persian sound system and say it by Persian pronunciation rather than Arabic.

The results of this research show that certain class of numbers which are called non-scale numbers demonstrate a great degree of code-switching while other scale numbers do not show much code-switching. More research is needed on Khuzestani Arabic to discover not only numerical code-switching but also lexical, syntactical, and phonological codeswitching as well.

\section{Appendix}

\begin{tabular}{|l|l|l|l|l|l|l|l|l|}
\hline No & $\begin{array}{l}\text { Study } \\
\text { Code }\end{array}$ & Sex & Age & $\begin{array}{l}\text { Marital } \\
\text { Status }\end{array}$ & $\begin{array}{l}\text { Parents' } \\
\text { Bilingualism }\end{array}$ & Class & Religion & Occupation \\
\hline 1 & $1 \mathrm{~A}$ & Male & 20 & Single & Bilingual & Working & Islam, Shia & Student \\
\hline 2 & $1 \mathrm{~B}$ & Female & 32 & Married & Bilingual & Working & Islam, Shia & Teacher \\
\hline 3 & $1 \mathrm{C}$ & Male & 30 & Married & Bilingual & Middle & Islam, Shia & Business \\
\hline 4 & $1 \mathrm{D}$ & Female & 31 & Single & Bilingual & Working & Islam, Shia & Customs \\
\hline 5 & $1 \mathrm{E}$ & Male & 18 & Single & Bilingual & Working & Islam, Shia & Student \\
\hline 6 & $2 \mathrm{~A}$ & Male & 36 & Married & Bilingual & Middle & Islam, Shia & Shopkeeper \\
\hline 7 & $2 \mathrm{~B}$ & Male & 19 & Single & Bilingual & Working & Islam, Shia & Salesman \\
\hline 8 & $2 \mathrm{C}$ & Male & 47 & Married & Bilingual & Working & Islam, Shia & Sailor \\
\hline 9 & $2 \mathrm{D}$ & Female & 24 & Single & Bilingual & Working & Islam, Shia & Student \\
\hline 10 & $2 \mathrm{E}$ & Female & 28 & Single & Bilingual & Working & Islam, Shia & Student \\
\hline 11 & $2 \mathrm{~F}$ & Female & 18 & Single & Bilingual & Middle & Islam, Shia & Student \\
\hline 12 & $2 \mathrm{G}$ & Male & 21 & Single & Bilingual & Working & Islam, Shia & Student \\
\hline
\end{tabular}




\begin{tabular}{|c|c|c|c|c|c|c|c|c|}
\hline 13 & $3 A$ & Male & 19 & Single & Bilingual & Working & Islam, Shia & Farmer \\
\hline 14 & $3 \mathrm{~B}$ & Female & 23 & Single & Bilingual & Working & Islam, Shia & Student \\
\hline 15 & $3 \mathrm{D}$ & Female & 22 & Single & Bilingual & Working & Islam, Shia & Student \\
\hline 16 & $3 \mathrm{E}$ & Female & 19 & Single & Bilingual & Working & Islam, Shia & Student \\
\hline 17 & $3 F$ & Female & 19 & Single & Bilingual & Working & Islam, Shia & Student \\
\hline 18 & $3 G$ & Female & 29 & Married & Bilingual & Working & Islam, Shia & Student \\
\hline 19 & $4 \mathrm{~A}$ & Male & 19 & Single & Bilingual & Working & Islam, Shia & Student \\
\hline 20 & 4B & Male & 22 & Single & Bilingual & Working & Islam, Shia & Shopkeeper \\
\hline 21 & $4 \mathrm{C}$ & Male & 35 & Married & Bilingual & Working & Islam, Shia & Office worker \\
\hline 22 & $4 \mathrm{D}$ & Female & 30 & Single & Bilingual & Middle & Islam, Shia & Sales manager \\
\hline 23 & $4 \mathrm{E}$ & Male & 22 & Single & Bilingual & Working & Islam, Shia & Farmer \\
\hline 24 & $4 \mathrm{~F}$ & Male & 26 & Single & Bilingual & Working & Islam, Shia & Electrician \\
\hline 25 & $5 A$ & Female & 18 & Single & Bilingual & High-mid & Islam, Shia & Student \\
\hline 26 & $5 B$ & Male & 20 & Single & Bilingual & Working & Islam, Shia & Student \\
\hline 27 & $5 \mathrm{C}$ & Male & 24 & Single & Bilingual & Working & Islam, Shia & Student \\
\hline 28 & $5 \mathrm{D}$ & Male & 19 & Single & Bilingual & Working & Islam, Shia & Baker \\
\hline 29 & $5 E$ & Female & 21 & Single & Bilingual & Working & Islam, Shia & Student \\
\hline 30 & $5 \mathrm{~F}$ & Male & 32 & Married & Bilingual & Working & Islam, Shia & Salesman \\
\hline 31 & $6 \mathrm{~A}$ & Female & 44 & Married & Mother & Working & Islam, Shia & Housewife \\
\hline 32 & $6 \mathrm{~B}$ & Female & 23 & Single & Bilingual & Middle & Islam, Shia & Student \\
\hline 33 & $6 \mathrm{D}$ & Male & 21 & Single & Bilingual & Middle & Islam, Shia & Student \\
\hline
\end{tabular}

\section{ences}

1. Bialystok, Ellen \& Codd, Judith (2997). Cardinal Limits: Evidence from Language Awareness and Bilingualism for Developing Concepts of Number. Cognitive Development, 12, 85-106 (1997).

2. Frenck-Mestre, Cheryl \& Vaid, Jyotsna (1993). Activation of Number Facts in Bilinguals. Memory \& Cognition. 1993, 2 (6) 809-918

3. Holmes, Janet (2008). An Introduction to Sociolinguistics, Third Edition. Pearson Education Limited.

4. Holmes. Janet \& Hazen. Kirk (2014). Research Methods in Sociolinguistics: A practical Guide. Wiley Blackwell \& Son, Inc.

5. Macizo, Pedro et al (2010). Second language Acquisition Influences the Processing of Number Words. Procedia Social Behavioral Sciences 9 (2010) 1128-1134.

6. Meyers-Scotton, Carol (1998). Code-Switching. Linguistics. Sociolinguistics. Blackwell Reference Online

7. Muysken, Pieter (2011). Code-switching. In R. Mesthrie (Ed), The Cambridge Handbook of Sociolinguistics (pp. 301-314). Cambridge University Press.

8. Rafiki Yohana Sebonde (2014). Code-switching or lexical borrowing: Numerals in Chasu language of rural Tanzania. Journal of Arts and Humanities (JAH), Volume -3, No.-3, March, 2014.

9. Roberts, Gareth (2000). Bilingualism and Number in Wales. International Journal of Bilingual Education and Bilingualism. Vol. 3, No. 1, 2000.

10. Shabibi, Maryam (2006). Word Order Variation in Khuzestani Arabic: A Language Contact Phenomenon. Shahid Chamran University.

11. Wardhaugh, Ronald (2010). An Introduction to Sociolinguistics, Third Edition. Wiley Blackwell. 